\title{
Takotsubo cardiomyopathy: etiology, diagnosis, and optimal management
}

This article was published in the following Dove Press journal:

Research Reports in Clinical Cardiology

29 October 2014

Number of times this article has been viewed

\section{Siu-Hin Wan \\ Jackson J Liang}

Department of Internal Medicine, Mayo Clinic and Foundation,

Rochester, MN, USA
Correspondence: Siu-Hin Wan Department of Internal Medicine, Mayo Clinic and Foundation, 200 First Street Southwest, Rochester, MN 55905, USA

Tel + I 5072664 I 56

Fax +I 5072845370

Email wan.siuhin@mayo.edu
Abstract: Takotsubo cardiomyopathy, also known as stress-induced cardiomyopathy or apical ballooning syndrome, is a condition of stress-induced apical hypokinesis in the setting of a preserved basal segment. It has become increasingly recognized and described. While it can mimic the presentation of an acute myocardial infarction, it is a transient phenomenon, and ventricular systolic function typically recovers completely. We review the relevant literature over the past 2 decades regarding the pathophysiology, diagnosis, epidemiology, management, and prognosis of this condition.

Keywords: apical ballooning syndrome, takotsubo cardiomyopathy, stress-induced cardiomyopathy, myocardial infarction, heart failure

\section{Introduction}

Takotsubo cardiomyopathy (TTC), also known as stress-induced cardiomyopathy or apical ballooning syndrome (ABS), is a condition most frequently characterized by dysfunction of the apical and mid-portions of the myocardium, with a relatively preserved or hyperkinetic base. ${ }^{1}$ Often, the condition is triggered by a physical or emotional stressor. ${ }^{2}$ The word takotsubo is Japanese for "octopus trap" (Figure 1), a jar-like shape that is the resulting configuration that can be demonstrated on left ventriculography when the base segment contracts with a relatively hypokinetic apical segment (Figure 2). The clinical significance of this entity is that the clinical presentation of TTC can be similar to a myocardial infarction, although there is an absence of or only mild coronary artery disease. ${ }^{3}$ More recently described variants of TTC have also included involvement of the base with preservation of the contractile function of the apex and mid-segments (Figure 3$).^{4}$

\section{Pathophysiology}

The underlying pathophysiology of TTC is not well understood, but is thought to be secondary to stress and resulting catecholamine release (Figure 4). Both physical and emotional stressors have been reported to precipitate the condition. The adrenalcardiac axis, which has been recently implicated in the adverse remodeling process with chronic heart failure, may also contribute to the pathogenesis of TTC. ${ }^{5}$ Studies in both rats and humans have implicated increased circulating catecholamine levels in the pathogenesis of the disease. ${ }^{6-8}$

While catecholamine release is a suspected contributory factor resulting in transient myocardial stunning, it remains unclear why the apex is often selectively 

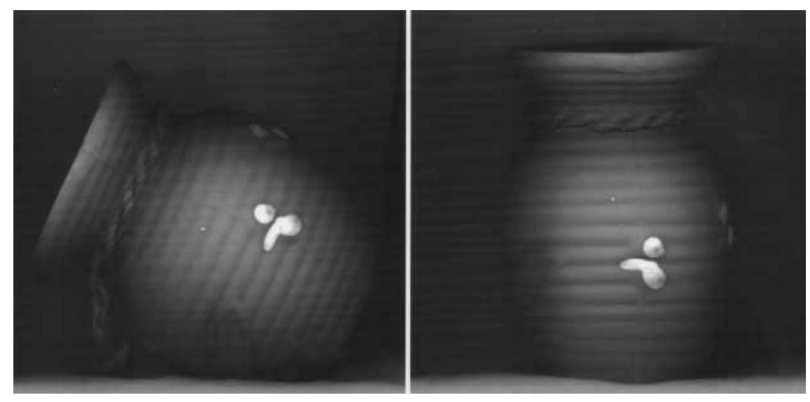

Figure I Takotsubo octopus trap.

Notes: Adapted from Kurisu S, Sato H, Kawagoe T, et al. Tako-tsubo-like left ventricular dysfunction with ST-segment elevation: a novel cardiac syndrome mimicking acute myocardial infarction. Am Heart J. 2002; 143:448-455. Copyright (C) 2002, with permission from Elsevier. ${ }^{17}$

involved, while basal contraction remains spared. Recent reports provide insight as to the possible causes of selective myocardium involvement, including a lack of three-layered structure of the myocardium at the ventricular apex and the distribution variation in adrenoreceptors in the heart. ${ }^{9,10}$ Neurogenic stunned myocardium has also been described as having the same pathophysiology as TTC. ${ }^{11}$ Reports have described that after catecholamine release, there is left ventricular basal hyperkinesis with subsequent mitral reduction, systolic anterior motion, and increased intraventricular pressure leads to apical ballooning. ${ }^{12}$

Many conditions may be the triggering event for TTC (Table 1). Gianni et al reported an identifiable emotional trigger in $27 \%$ of subjects and a physical trigger in $38 \% .{ }^{8}$ Two conditions associated with transient myocardial dysfunction that lend support to the catecholamine pathophysiology of TTC include that of pheochromocytoma and that associated with a massive cerebral vascular accident. Patients with pheochromocytoma have catecholamine-related cardiomyopathy from cardiac toxicity and remodeling. ${ }^{13,14}$ Additionally, severe neurologic injury, such as subarachnoid hemorrhage, may be associated with electrocardiogram abnormalities and left ventricular systolic dysfunction, a phenomenon referred to as neurogenic stunned myocardium. ${ }^{15}$
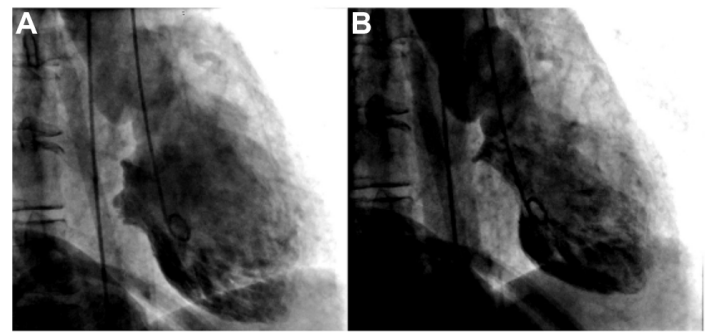

Figure 2 Left ventriculogram with apical ballooning during diastole (A) and systole (B).

Notes: Adapted from Liang JJ, Cha YM, Oh JK, Prasad A. Sudden cardiac death: an increasingly recognized presentation of apical ballooning syndrome (takotsubo cardiomyopathy). Heart Lung. 2013;42:270-272. Copyright (@ 2013, with permission from Elsevier. ${ }^{15}$
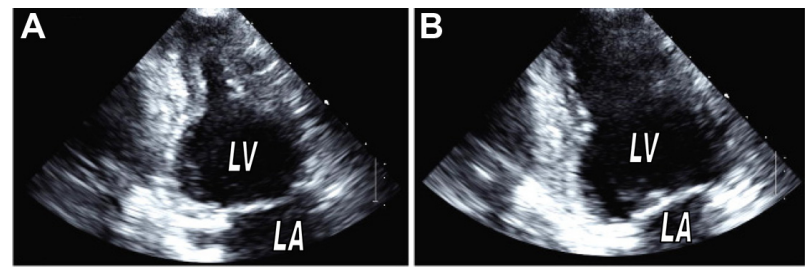

Figure 3 (A and B) Echocardiography demonstrating inverted takotsubo cardiomyopathy. Notes: (A) Systole with basal left ventricular dilatation; (B) diastole. Adapted from Liang JJ, Kurklinsky AK, Peterson TJ, Freeman WK, Oh JK. Post-procedural inverted takotsubo cardiomyopathy. Heart Lung Circ. 2013;22:1060-1061. Copyright () 2013, with permission from Elsevier. ${ }^{44}$

Abbreviations: LA, left atrium, LV, left ventricle.

Additional potential mechanisms of action include coronary artery vasospasm and dysfunction of the coronary microvasculature. There is evidence of coronary spasms in some subjects. ${ }^{16}$ Spasms of multiple coronary arteries have been elicited with provocation testing. ${ }^{17}$ Using technetium- 99 cardiac single-photon emission computed tomography imaging in a study of ten subjects with TTC, Ito et al showed that impaired coronary microcirculation may be a contributing factor to the pathophysiology of this condition. ${ }^{18}$ TTC has been described in association with rheumatic conditions (such as systemic lupus erythematosus, systemic sclerosis, polymyositis, and Raynaud's phenomenon).$^{5,19,20}$ Melchiorre et al have interestingly proposed that ABS may result from "myocardial Raynaud's phenomenon", due to transient myocardial ischemia in the setting of vasospasm of the coronary microvasculature. ${ }^{20}$

Previously, there have also been proposals that the pathophysiology may be related to an aborted acute myocardial infarction. Specifically, it has been suggested that an anterior infarct, with a long left anterior descending artery, may result in preferential hypokinesis of the apex. However, in a retrospective study of 97 subjects with TTC, a long left anterior descending artery wrapping around the apex was not more commonly found compared to matched controls. ${ }^{21}$

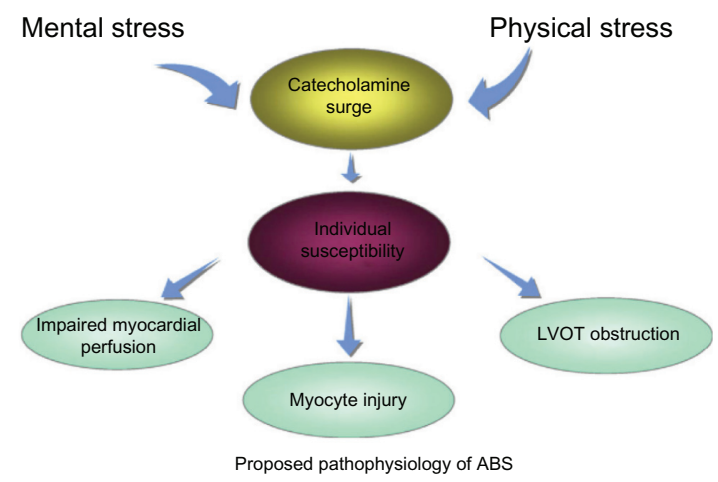

Figure 4 Proposed pathophysiology of apical ballooning syndrome (ABS). Notes: Adapted from Prasad A, Lerman A, Rihal CS. Apical ballooning syndrome (tako-tsubo or stress cardiomyopathy): a mimic of acute myocardial infarction. Am Heart J. 2008; I55:408-4I7. Copyright (c) 2008, with permission from Elsevier. ${ }^{46}$ Abbreviation: LVOT, left ventricular outflow tract. 
Table I Triggering events and associated conditions for takotsubo cardiomyopathy ${ }^{13,16,44,45,57}$

\begin{tabular}{ll}
\hline Physical/medical triggers & Emotional triggers \\
\hline Stress state & Major financial losses \\
Motor vehicle accident & Death, severe illness, or \\
Critical illness & injury of family member, \\
Cerebrovascular accident & friend, or pet \\
Epilepsy & Natural disasters (eg, \\
Asthma exacerbation & earthquake, tornado, etc) \\
Acute abdominal pain & Public speaking \\
Surgical procedures & Being in an argument \\
Pheochromocytoma & Receiving bad news \\
Exogenous catecholamines (inhaled $\beta$ - & Moving to new residence \\
agonists, methylxanthines, epinephrine, & Car accident \\
amphetamines, cocaine) & Surprise party \\
Severe pain & Legal proceedings \\
Cardiac stress test & \\
Thyrotoxicosis & \\
Opiate withdrawal & \\
Alcohol consumption & \\
Hyperlipidemia & \\
Smoking & \\
Alcohol & \\
Anxiety &
\end{tabular}

\section{Epidemiology}

While the exact epidemiology remains unclear, TTC is often discovered in a patient initially thought to have had a myocardial infarction and subsequently found to have normal coronary arteries on coronary angiography. While this condition has been increasingly recognized due to increased awareness of the disease along with the widespread use of echocardiography, the incidence and prevalence likely remain underestimated. Ventricular arrhythmias causing outof-hospital arrest have been estimated to account for $1 \%$ of all cases of ABS, suggesting that the actual incidence of ABS is likely much higher. ${ }^{22}$ Patients dying of out-of-hospital arrest who have normal-appearing hearts and coronary arteries at autopsy in whom death is attributed to unknown causes may actually be due to ABS. ${ }^{15}$ Small series have demonstrated that $1 \%-2 \%$ of those with suspected acute coronary syndrome actually have TTC. ${ }^{23}$ Summers et al suggested that there may be a connection with psychiatric disorders, specifically the anxiety disorders. ${ }^{24}$

A genetic predisposition to the development of the condition has been hypothesized, as suggested by the occurrence in multiple family members. ${ }^{25,26}$ Research into specific genes has also suggested a possible inheritance of the condition, although this remains controversial and further research is required. ${ }^{27,28}$ TTC is also more commonly reported in women than men, especially postmenopausal women. A systematic review of seven case series reported that $82 \%-100 \%$ of reported cases occurred in postmenopausal women with mean age $62-75$ years. ${ }^{29}$ Similarly, Wittstein et al reported in a study of 19 patients that $95 \%$ were women and the median age was 63 years. ${ }^{7}$ The proportion of afflicted women has been shown to increase with age. ${ }^{30}$ There have also been studies on the seasonal and regional variation of TTC, and it has been found that admissions related to TTC are more common among the summer and fall months compared to winter, with a peak in September and greatest regional significance in areas subject to large temperature variations throughout the year. ${ }^{31}$ This pattern is in contrast with seasonal distribution of acute myocardial infarctions, and further studies are needed to determine the underlying pathophysiology of TTC variations associated with catecholamine release and stress.

While initially described in Japan, TTC has now been widely reported across all ethnicities and populations. In 2003, Desmet et al reported on 13 Caucasian patients in Europe, 12 of whom were women, with a mean age of 62 years. ${ }^{32}$ There are unfortunately few data specifically on the incidence of the condition among different races, given the overall low prevalence of TTC. However, there have been reports of similarities in presentation among African American and non-African American women with TTC. ${ }^{33}$ Furthermore, in comparing the syndrome among Asians versus Caucasians, it was found that Asians more frequently had electrocardiographic findings of ST elevations versus T-wave inversions in the Caucasian group. ${ }^{34}$ Further studies with large populations are needed to better characterize the variability in incidence, prevalence, and presentation of those with TTC and varying demographics.

\section{Diagnosis}

Many subjects with TTC often initially present for medical care with symptoms concerning for an acute coronary syndrome. ${ }^{35}$ The initial differential diagnosis is often broad, and may include acute myocardial infarction, coronary artery vasospasm or Prinzmetal's angina, drug-induced (cocaine) vasospasm, spontaneous coronary artery dissection, myocardial bridging, myocarditis, pericarditis, and endocarditis. While some of these conditions are benign or self-limited, others are life-threatening and require emergent diagnosis and intervention. Common presenting symptoms include substernal chest pain, dyspnea, diaphoresis, and/or shock. In a study of 88 subjects in Japan with TTC, Tsuchihashi et al reported that $67 \%$ of subjects had chest symptoms, $90 \%$ had ST elevations, 27\% had Q-wave abnormalities, 97\% had T-wave inversions, and 56\% had elevated cardiac biomarkers. ${ }^{16}$ Furthermore, Ogura et al looked specifically at whether 
specific characteristics on a 12-lead electrocardiogram can be used to differentiate from acute myocardial infarction. In their small cohort of 13 subjects, they noted that a ratio greater than 1 of the amount of ST elevation in leads V4-V6 compared to leads V1-V3 is sensitive and specific to TTC, and combined with the absence of reciprocal changes had a specificity of $100 \%$ in their study population. ${ }^{36}$ Low QRS voltage as well as attenuation transiently of the QRS amplitude have also been associated with TTC, and may be useful in differentiating against acute myocardial infarction. ${ }^{37}$

An acute decompensation associated with myocardial hypokinesis may also result in acute heart-failure symptoms and systemic hypoperfusion. As TTC results in apical hypokinesis with a preserved or hypercontractile base, dynamic left ventricular outflow obstruction may exist, ${ }^{38}$ along with reversible systolic anterior motion of the mitral valve and functional mitral regurgitation. ${ }^{38-40}$

Given the similarity of the presenting symptoms with those of myocardial infarction, patients with TTC often undergo extensive cardiac workup at initial presentation. Electrocardiographic abnormalities are very common in those with TTC. ST-segment elevation is a common finding, most commonly in the anterior leads. T-wave inversions, QT and QTc prolongation, and Q-wave abnormalities are also commonly found. Cardiac biomarkers including troponins and creatinine kinase are often elevated. However, as opposed to the typical time course of cardiac biomarkers in an acute myocardial infarction, the intensity of laboratory-marker elevation is usually less pronounced in TTC. In a study of 59 subjects with TTC, Sharkey et al reported the peak troponin $\mathrm{T}$ level to be lower $(0.64+/-0.86 \mathrm{ng} / \mathrm{mL})$ than those with acute myocardial infarction $(3.88+/-4.9 \mathrm{ng} / \mathrm{mL}) .{ }^{41} \mathrm{On}$ cardiac angiography, the coronary arteries do not demonstrate coronary artery occlusions corresponding to the degree and areas of left ventricular dysfunction. However, given that many patients often are elderly in age, it is not uncommon for TTC to exist concurrently with some degree of coronary artery disease.

Transthoracic echocardiography and left ventriculography are the defining modalities for the diagnosis of TTC. More recently, cardiac magnetic resonance imaging has also been used to characterize cardiac function. Specifically, there is an absence of late gadolinium enhancement on cardiac magnetic resonance imaging compared to acute myocardial infarction. ${ }^{23}$ Additionally, myocardial edema may be seen, although this is not specific to TTC, as this may also be present in myocarditis or an acute myocardial infarction. ${ }^{23}$ Whereas there is usually a global hypokinesis with a myocardial infarction, there is a characteristic pattern that is seen in TTC on imaging, with hypokinesis or dyskinesis of the apical half of the myocardium and relatively preserved functioning of the remainder of the left ventricle. As previously mentioned, left ventricular outflow obstruction may also be observed, given this unique pattern of myocardial dysfunction. ${ }^{38}$ In comparing regional wall-motion abnormalities in patients with TTC and aborted anterior myocardial infarction as seen on biplane left ventriculography, a greater and more diffuse degree of regional wall-motion abnormalities was identified in those with TTC. Additionally, researchers interestingly identified the presence of systolic dysfunction in the posterolateral segment in the left anterior oblique projection to be both sensitive (81\%) and specific (100\%) for TTC, suggesting that biplane (as opposed to single-plane) left ventriculography during coronary angiography may be helpful in distinguishing the two conditions. ${ }^{42}$

Additionally, there have been further reports of different hypokinesis patterns that have also fallen under the umbrella of TTC. In a study of 35 patients in Germany with transient left ventricular dysfunction, atypical patterns of cardiac dysfunction, namely mid-ventricular hypokinesis instead of apical hypokinesis, in $40 \%$ of subjects were described. ${ }^{43}$ In a study of 276 patients, Eitel et al reported that $17 \%$ of subjects had the mid-ventricular variant, while $1 \%$ had the basal variant. ${ }^{23} \mathrm{~A}$ case of a woman who developed inverted TTC with basal dilatation following bronchoscopy has also been reported. ${ }^{44}$ Furthermore, $34 \%$ of subjects also demonstrated dysfunction of the right ventricle in addition to the left ventricle. ${ }^{23}$ Those with the inverted TTC variant may develop the condition at a younger age with greater probability of identification of a stressful trigger compared to the epidemiology of traditional TTC. ${ }^{45}$

There have been proposed Mayo Clinic diagnostic criteria for TTC. ${ }^{46}$ All four of the following conditions must be met in order for the diagnosis to be made. First, there must be transient hypokinesis or akinesis of the mid-portion of the left ventricle. The abnormalities in wall motion should not conform to the territory of a single coronary artery. Second, on coronary angiography, there must be an absence of obstructive coronary disease or plaque rupture. Third, there must be new abnormalities on the electrocardiogram, which may be ST-segment elevations or T-wave inversions, or there may be elevations in cardiac biomarkers. Fourth, there must not be the presence of a pheochromocytoma or myocarditis. Note that these diagnostic criteria do not specifically include the presence of a stressful trigger. While a history of an identifiable inciting factor supports the diagnosis of TTC, 
it is not absolutely required to make the diagnosis, as the inciting factor often remains unidentified.

Given the likely contribution of elevated serum catecholamines toward the pathophysiology TTC, it has been proposed that serum catecholamine measurements may be used for the diagnosis of the condition. However, Madhavan et al demonstrated in their study population that catecholamine and cortisol levels were not elevated, questioning the utility of such a measurement. ${ }^{47}$

\section{Management and prognosis}

Despite the often-apparently severe presentation of those with TTC, by definition it is a transient condition, and symptoms will usually resolve without the need for invasive interventions. When cardiogenic shock and hemodynamic instability are present, more aggressive and invasive interventions may be required to provide short-term support.

Patients should have continuous cardiac monitoring in the acute setting, due to the risk for ventricular arrhythmias. While implantable cardiac defibrillators are not indicated in the acute setting given the reversibility of the disease, further studies may evaluate the use of wearable cardioverter defibrillators in the acute setting for patients with left ventricular systolic dysfunction until recovery. ${ }^{15}$ Given the QT prolongation associated with TTC, torsades de pointes is also a potential complication of the condition. ${ }^{48,49} \mathrm{As}$ such, electrolytes must be monitored closely and replaced as needed, and QT-prolonging medications should be used judiciously when necessary.

Commonly used medications for the initial management of TTC include standard systolic heart-failure medications such as angiotensin-converting enzyme inhibitors, diuretics, and $\beta$-blockers. ${ }^{30}$ In the presence of concurrent mild-tomoderate atherosclerosis, aspirin has also been commonly used. ${ }^{29}$ There have not been established guidelines, however, as to the exact treatment duration. Given that TTC is a transient condition, these pharmacological agents are often not continued indefinitely in the absence of other indications. One to 4 weeks of medication treatment has been used, and most patients regain cardiac function within this time period. Since patients may be prone to recurrence, some clinicians prefer to use long-term $\beta$-blockers for secondary prevention, although this remains controversial. Elesber et al found an average annual recurrence rate of $2.9 \%$ over the initial several years for TTC, and although many patients were prescribed $\beta$-blockers, given the smaller study population, they did not find a statistically significant prevention of event recurrence. ${ }^{50}$ Additionally, angiotensin-converting enzyme inhibitors and angiotensin-receptor blockers, rather than $\beta$-blockers, have also been associated with reduced risk of recurrence. ${ }^{51}$

With more severe hemodynamic instability refractory or intolerant to fluid resuscitation, inotropic support, such as dobutamine and dopamine, may be used in those without evidence of left ventricular outflow obstruction. However, among those with left ventricular outflow obstruction, agents with positive inotropic and chronotropic effects may worsen the outflow-tract obstruction and decrease cardiac output, especially in the setting of catecholamine excess. Rather, in patients with evidence of left ventricular outflow obstruction, $\beta$-blockers will reduce heart rate, improve filling, and may resolve hemodynamic instability. Although frequently used for hemodynamic support in patients with cardiogenic shock, intra-aortic balloon-pump counterpulsation may actually worsen cardiac output in TTC patients who have left ventricular outflow-tract obstruction by reducing afterload. ${ }^{18}$ For hypotensive patients requiring vasopressor support, an $\alpha$-adrenergic-receptor agonist, such as phenylephrine, should be preferentially selected, since they have less inotropic effect and will be less likely to increase the outflow-tract obstruction. $^{52}$

Given the risk of thromboembolism with intracardiac stasis when severe systolic dysfunction is present, we feel that anticoagulation is also an important consideration based on information extrapolated from acute myocardial infarction. At a time of increased stasis and decreased flow, intracardiac thrombus may develop and subsequently embolize to the brain or other systemic organs. Those with an identified thrombus on echocardiography or other cardiac imaging modalities may benefit from the use of anticoagulation to prevent systemic embolization. There is no wide consensus regarding the optimal duration of anticoagulation, and a treatment duration of 3 months (or until resolution of apical hypokinesis, whichever occurs later), is reasonable given the transient nature of the condition. Clinical decisions are often made based on data extrapolated from thrombus formation after acute myocardial infarction, one such study reporting the presence of intracardiac thrombus in $3.7 \%$ of patients 2 weeks following acute myocardial infarction. ${ }^{53}$

Common in-hospital complications, as reported by Tsuchihashi et al, include pulmonary edema (22\%), cardiogenic shock (15\%), and ventricular arrhythmia (9\%). ${ }^{16}$ Arrhythmias are common, affecting over a quarter of those with TTC, and furthermore, while atrial fibrillation was the most common arrhythmia (7\%), men are more likely than women to have life-threatening ventricular tachyarrhythmias compared to atrial fibrillation or flutter. ${ }^{54}$ 
Given the transient nature of TTC, prognosis is generally favorable. There have however been reported cases of persistent apical ballooning, although this is not the norm in most patients. ${ }^{55,56}$ TTC has a hospital-mortality rate of up to $8 \%$, with a median hospital-stay length of 4 days, and an $11.4 \%$ 4-year recurrence rate..$^{8,41,50}$ The vast majority of those who survive will experience recovery of ventricular function within 1-4 weeks.

\section{Conclusion}

TTC, a condition of stress-induced localized cardiac dysfunction, has been increasingly described. Prompt recognition and differentiation from an acute coronary syndrome is important for management. While a physical or emotional stressor often precedes the cardiomyopathy, a trigger is not always identified. Management in most cases involves conservative and supportive treatment. Recognition of acute and severe complications, such as hypotension, ventricular arrhythmias, and thromboembolism, is essential for escalation in aggressive management strategies. Prognosis is excellent in most cases of patients who survive the initial acute episode, and recovery of left ventricular function usually occurs within weeks.

\section{Disclosure}

The authors report no conflicts of interest in this work.

\section{References}

1. Dote K, Sato H, Tateishi H, Uchida T, Ishihara M. [Myocardial stunning due to simultaneous multivessel coronary spasms: a review of 5 cases]. J Cardiol. 1991;21:203-214. Japanese.

2. Hachamovitch R, Chang JD, Kuntz RE, Papageorgiou P, Levin MS, Goldberger AL. Recurrent reversible cardiogenic shock triggered by emotional distress with no obstructive coronary disease. Am Heart J. 1995;129:1026-1028.

3. Bybee KA, Prasad A, Barsness GW, et al. Clinical characteristics and thrombolysis in myocardial infarction frame counts in women with transient left ventricular apical ballooning syndrome. Am J Cardiol. 2004;94:343-346.

4. Win CM, Pathak A, Guglin M. Not takotsubo: a different form of stressinduced cardiomyopathy - a case series. Congest Heart Fail. 2011;17: $38-41$.

5. Liang JJ, Bishu KG, Anavekar NS. Apical ballooning syndrome in polymyositis following placement of pericardial drainage catheter. J Cardiovasc Dis. 2014;2(3):174-176.

6. Paur H, Wright PT, Sikkel MB, et al. High levels of circulating epinephrine trigger apical cardiodepression in a $\beta 2$-adrenergic receptor/ Gi-dependent manner: a new model of takotsubo cardiomyopathy. Circulation. 2012;126:697-706.

7. Wittstein IS, Thiemann DR, Lima JA, et al. Neurohumoral features of myocardial stunning due to sudden emotional stress. $N$ Engl J Med. 2005;352:539-548.

8. Gianni M, Dentali F, Grandi AM, Sumner G, Hiralal R, Lonn E. Apical ballooning syndrome or takotsubo cardiomyopathy: a systematic review. Eur Heart J. 2006;27:1523-1529.

9. Stöllberger C, Finsterer J, Schneider B. Transient left ventricular dysfunction (tako-tsubo phenomenon): findings and potential pathophysiological mechanisms. Can J Cardiol. 2006;22:1063-1068.
10. Zhan ZQ, Wang CQ, Nikus KC, Sclarovsky S. Correlation between ECG presentation and cardiovascular magnetic resonance imaging in takotsubo cardiomyopathy. J Electrocardiol. 2013;46:343-345.

11. Guglin M, Novotorova I. Neurogenic stunned myocardium and takotsubo cardiomyopathy are the same syndrome: a pooled analysis. Congest Heart Fail. 2011;17:127-132.

12. Ieva R, Santoro F, Ferraretti A, et al. Hyper-acute precipitating mechanism of tako-tsubo cardiomyopathy: in the beginning was basal hyperkinesis? Int J Cardiol. 2013;167:e55-e57.

13. Kassim TA, Clarke DD, Mai VQ, Clyde PW, Mohamed Shakir KM. Catecholamine-induced cardiomyopathy. Endocr Pract. 2008;14: 1137-1149.

14. Fineschi V, Silver MD, Karch SB, et al. Myocardial disarray: an architectural disorganization linked with adrenergic stress? Int J Cardiol. 2005;99:277-282.

15. Liang JJ, Cha YM, Oh JK, Prasad A. Sudden cardiac death: an increasingly recognized presentation of apical ballooning syndrome (takotsubo cardiomyopathy). Heart Lung. 2013;42:270-272.

16. Tsuchihashi K, Ueshima K, Uchida $T$, et al. Transient left ventricular apical ballooning without coronary artery stenosis: a novel heart syndrome mimicking acute myocardial infarction. Angina PectorisMyocardial Infarction Investigations in Japan. $\mathrm{J} \mathrm{Am}$ Coll Cardiol. 2001;38:11-18.

17. Kurisu S, Sato H, Kawagoe T, et al. Tako-tsubo-like left ventricular dysfunction with ST-segment elevation: a novel cardiac syndrome mimicking acute myocardial infarction. Am Heart J. 2002;143:448-455.

18. Ito K, Sugihara H, Katoh S, Azuma A, Nakagawa M. Assessment of takotsubo (ampulla) cardiomyopathy using $99 \mathrm{mTc}$-tetrofosmin myocardial SPECT - comparison with acute coronary syndrome. Ann Nucl Med. 2003;17:115-122.

19. Meyer Neto JG, Benchimol CB, Penna GL, Carvalho LA, Pessoa MC. A rare association of systemic lupus erythematosus, morbid obesity and takotsubo syndrome. Arq Bras Cardiol. 2006;87:e116-e121.

20. Melchiorre D, Bernardo P, Conforti ML, et al. Tako-tsubo-like syndrome in systemic sclerosis: a sign of myocardial Raynaud phenomenon? Ann Rheum Dis. 2008;67:898-899.

21. Hoyt J, Lerman A, Lennon RJ, Rihal CS, Prasad A. Left anterior descending artery length and coronary atherosclerosis in apical ballooning syndrome (takotsubo/stress induced cardiomyopathy). Int J Cardiol. 2010;145:112-115.

22. Syed FF, Asirvatham SJ, Francis J. Arrhythmia occurrence with takotsubo cardiomyopathy: a literature review. Europace. 2011;13: $780-788$.

23. Eitel I, von Knobelsdorff-Brenkenhoff F, Bernhardt P, et al. Clinical characteristics and cardiovascular magnetic resonance findings in stress (takotsubo) cardiomyopathy. JAMA. 2011;306:277-286.

24. Summers MR, Lennon RJ, Prasad A. Pre-morbid psychiatric and cardiovascular diseases in apical ballooning syndrome (tako-tsubo/ stress-induced cardiomyopathy): potential pre-disposing factors? $\mathrm{J} \mathrm{Am}$ Coll Cardiol. 2010;55:700-701.

25. Pison L, De Vusser P, Mullens W. Apical ballooning in relatives. Heart. 2004;90:e67.

26. Kumar G, Holmes DR Jr, Prasad A. "Familial" apical ballooning syndrome (takotsubo cardiomyopathy). Int J Cardiol. 2010;144: 444-445.

27. Handy AD, Prasad A, Olson TM. Investigating genetic variation of adrenergic receptors in familial stress cardiomyopathy (apical ballooning syndrome). J Cardiol. 2009;54:516-517.

28. Sharkey SW, Maron BJ, Nelson P, Parpart M, Maron MS, Bristow MR. Adrenergic receptor polymorphisms in patients with stress (tako-tsubo) cardiomyopathy. J Cardiol. 2009;53:53-57.

29. Bybee KA, Kara T, Prasad A, et al. Systematic review: transient left ventricular apical ballooning: a syndrome that mimics ST-segment elevation myocardial infarction. Ann Intern Med. 2004;141:858-865.

30. Buja P, Zuin G, Di Pede F, et al. Long-term outcome and sex distribution across ages of left ventricular apical ballooning syndrome. J Cardiovasc Med (Hagerstown). 2008;9:905-909. 
31. Aryal MR, Pathak R, Karmacharya P, Donato AA. Seasonal and regional variation in takotsubo cardiomyopathy. Am J Cardiol. 2014;113:1592.

32. Desmet WJ, Adriaenssens BF, Dens JA. Apical ballooning of the left ventricle: first series in white patients. Heart. 2003;89:1027-1031.

33. Qaqa A, Daoko J, Jallad N, Aburomeh O, Goldfarb I, Shamoon F. Takotsubo syndrome in African American vs non-African American women. West J Emerg Med. 2011;12:218-223.

34. Núñez-Gil IJ, Luaces M, Garcia-Rubira JC, Zamorano J. Electrocardiographic criteria in takotsubo cardiomyopathy and race differences: Asians versus Caucasians. J Am Coll Cardiol. 2010;56: 1433-1434; author reply 1434.

35. Sharkey SW, Lesser JR, Zenovich AG, et al. Acute and reversible cardiomyopathy provoked by stress in women from the United States. Circulation. 2005;111:472-479.

36. Ogura R, Hiasa Y, Takahashi T, et al. Specific findings of the standard 12-lead ECG in patients with 'takotsubo' cardiomyopathy: comparison with the findings of acute anterior myocardial infarction. Circ J. 2003;67:687-690.

37. Madias JE. Transient attenuation of the amplitude of the QRS complexes in the diagnosis of takotsubo syndrome. Eur Heart J Acute Cardiovasc Care. 2014;3:28-36.

38. Villareal RP, Achari A, Wilansky S, Wilson JM. Anteroapical stunning and left ventricular outflow tract obstruction. Mayo Clin Proc. 2001;76: 79-83.

39. Shah BN, Curzen NP. Reversible systolic anterior motion of the mitral valve and left ventricular outflow tract obstruction in association with takotsubo syndrome. Echocardiography. 2011;28:921-924.

40. Brunetti ND, Ieva R, Rossi G, et al. Ventricular outflow tract obstruction, systolic anterior motion and acute mitral regurgitation in tako-tsubo syndrome. Int J Cardiol. 2008;127:e152-e157.

41. Sharkey SW, Lesser JR, Menon M, Parpart M, Maron MS, Maron BJ. Spectrum and significance of electrocardiographic patterns, troponin levels, and thrombolysis in myocardial infarction frame count in patients with stress (tako-tsubo) cardiomyopathy and comparison to those in patients with ST-elevation anterior wall myocardial infarction. Am J Cardiol. 2008;101:1723-1728.

42. Patel SM, Lennon RJ, Prasad A. Regional wall motion abnormality in apical ballooning syndrome (takotsubo/stress cardiomyopathy): importance of biplane left ventriculography for differentiating from spontaneously aborted anterior myocardial infarction. Int J Cardiovasc Imaging. 2012;28:687-94.

43. Kurowski V, Kaiser A, von Hof K, et al. Apical and midventricular transient left ventricular dysfunction syndrome (tako-tsubo cardiomyopathy): frequency, mechanisms, and prognosis. Chest. 2007;132:809-816.
44. Liang JJ, Kurklinsky AK, Peterson TJ, Freeman WK, Oh JK. Post-procedural inverted takotsubo cardiomyopathy. Heart Lung Circ. 2013;22:1060-1061.

45. Ramaraj R, Movahed MR. Reverse or inverted takotsubo cardiomyopathy (reverse left ventricular apical ballooning syndrome) presents at a younger age compared with the mid or apical variant and is always associated with triggering stress. Congest Heart Fail. 2010;16:284-286.

46. Prasad A, Lerman A, Rihal CS. Apical ballooning syndrome (tako-tsubo or stress cardiomyopathy): a mimic of acute myocardial infarction. Am Heart J. 2008;155:408-417.

47. Madhavan M, Borlaug BA, Lerman A, Rihal CS, Prasad A. Stress hormone and circulating biomarker profile of apical ballooning syndrome (takotsubo cardiomyopathy): insights into the clinical significance of B-type natriuretic peptide and troponin levels. Heart. 2009;95: 1436-1441.

48. Behr ER, Mahida S. Takotsubo cardiomyopathy and the long-QT syndrome: an insult to repolarization reserve. Europace. 2009;11: 697-700.

49. Madias C, Fitzgibbons TP, Alsheikh-Ali AA, et al. Acquired long QT syndrome from stress cardiomyopathy is associated with ventricular arrhythmias and torsades de pointes. Heart Rhythm. 2011;8:555561.

50. Elesber AA, Prasad A, Lennon RJ, Wright RS, Lerman A, Rihal CS. Four-year recurrence rate and prognosis of the apical ballooning syndrome. J Am Coll Cardiol. 2007;50:448-452.

51. Singh K, Carson K, Usmani Z, Sawhney G, Shah R, Horowitz J. Systematic review and meta-analysis of incidence and correlates of recurrence of takotsubo cardiomyopathy. Int J Cardiol. 2014;174:696-701.

52. Redmond M, Knapp C, Salim M, Shanbhag S, Jaumdally R. Use of vasopressors in takotsubo cardiomyopathy: a cautionary tale. $\mathrm{BrJ}$ Anaesth. 2013;110:487-488.

53. Greaves SC, Zhi G, Lee RT, et al. Incidence and natural history of left ventricular thrombus following anterior wall acute myocardial infarction. Am J Cardiol. 1997;80:442-448.

54. Pant S, Deshmukh A, Mehta K, et al. Burden of arrhythmias in patients with takotsubo cardiomyopathy (apical ballooning syndrome). Int $J$ Cardiol. 2013;170:64-68.

55. Lee PH, Song JK, Park IK, et al. Takotsubo cardiomyopathy: a case of persistent apical ballooning complicated by an apical mural thrombus. Korean J Intern Med. 2011;26:455-459.

56. Shim IK, Kim BJ, Kim H, Lee JW, Cha TJ, Heo JH. A case of persistent apical ballooning complicated by apical thrombus in takotsubo cardiomyopathy of systemic lupus erythematosus patient. J Cardiovasc Ultrasound. 2013;21:137-139.

57. Deshmukh A, Kumar G, Pant S, Rihal C, Murugiah K, Mehta JL. Prevalence of takotsubo cardiomyopathy in the United States. Am Heart J. 2012;164:66-71. e1.
Research Reports in Clinical Cardiology

\section{Publish your work in this journal}

Research Reports in Clinical Cardiology is an international, peerreviewed, open access journal publishing original research, reports, editorials, reviews and commentaries on all areas of cardiology in the clinic and laboratory. The manuscript management system is completely online and includes a very quick and fair peer-review system.

\section{Dovepress}

Visit http://www.dovepress.com/testimonials.php to read real quotes from published authors. 